\title{
Factors Influencing Contraceptive Use Among Rural Women in ljero - Local Government Area of Ekiti - State, Nigeria
}

\author{
Awogbami Stephen Olalekan ${ }^{1}$, Ogunrinde Modupe Elizabeth ${ }^{2}$, Adewumi Micheal Onasanmi $^{1}$, \\ Awe Omotola $^{3}$, Steve - Awogbami Oluseyi ${ }^{4}$ \\ ${ }^{1}$ Department of Environmental Health Technology, College of Health Sciences and Technology, Ijero-Ekiti, Ekiti State, Nigeria \\ ${ }^{2}$ Department of Community and Public Health, College of Health Sciences and Technology, Ijero-Ekiti, Ekiti State, Nigeria \\ ${ }^{3}$ Department of Human Nutrition and Dietetics, College of Health Sciences and Technology, Ijero-Ekiti, Ekiti State, Nigeria \\ ${ }^{4}$ Department of General Studies, College of Health Sciences and Technology, Ijero-Ekiti, Ekiti State, Nigeria
}

Email address:

Steve4real2016@gmail.com (A. S. Olalekan),duperinde2014@gmail.com (O. M. Elizabeth),

adewumiat90m@yahoo.com (A. M. Onasanmi), aweomotola01@gmail.com (A. Omotola),

seyisteveawogbami@gmail.com (Steve - Awogbami O.)

\section{To cite this article:}

wogbami Stephen Olalekan, Ogunrinde Modupe Elizabeth, Adewumi Micheal Onasanmi, Awe Omotola, Steve - Awogbami Oluseyi. Factors Influencing Contraceptive Use Among Rural Women in Ijero - Local Government Area of Ekiti - State, Nigeria. Central African Journal of Public Health. Vol. 6, No. 4, 2020, pp. 200-206. doi: 10.11648/j.cajph.20200604.13

Received: May 31, 2020; Accepted: June 17, 2020; Published: July 4, 2020

\begin{abstract}
This study was designed to essentially determine the relationship between socio-demographic factors and contraceptive use. This was with the view of identifying existing barriers to contraceptive use in the county. The study adopted a community-based, descriptive cross-sectional study. The target population was women of reproductive age, 15 to 49 years living in Ijero Local Government Area of Ekiti State. Using the sample size calculation formula, a sample of 250 women was randomly selected for the study. Data was collected using questionnaires translated and back-translated between the English and the local Yoruba language. Data analysis was performed using SPSS version 20 to generate descriptive and inferential statistics such as contingency tables and bar charts. Chi square was used to find relationship between non parametric variables by testing for association at $5 \%(\mathrm{p}=0,05)$ level of significance. Key findings of the study reveals that respondents were young adults and largely in their reproductive age span, more than three-quarters were Christian, more than two-fifths have secondary school education; $76.8 \%$ of the sample were working; nine out of every ten women have heard about contraceptives, many respondents have used at least one type of conceptive method, Injections method was the most popular conceptive method among the respondents, and more than $30.4 \%$ of the respondents heard about contraceptives through television. Results further show that: women have considerable knowledge on different aspects of the modern contraceptives, $89.6 \%$ of women were of the view that modern contraceptive prevents unwanted pregnancy; $39.2 \%$ perceived modern contraceptive as something that can boost husband fidelity (39.2\%); the most common negative effect of modern contraceptives reported is irregular menstruation among the users; and women in the study area have used injections $(22 \%)$ and condoms $(20.8 \%)$ more than any other modern contraceptive methods.
\end{abstract}

Keywords: Socio-demograhics, Contraceptives, Rural Women, Fertility Rate, Ekiti State, Nigeria

\section{Introduction}

Increasing the level of contraceptives use among women of child bearing age is an important component of many national population and developmental programs in sub-
Saharan Africa; however the prevalence use of these methods is still low despite the efforts of many governmental and nongovernmental agencies (NGOs). Many authors however raised the alarm that a stage would reach in the world when food supply would not match its population growth. [1] While most of the developed countries have managed to 
overcome this, the issue of population growth and consequent food shortage in developing countries is overwhelming. [2] This expansive population growth rate has been attributed to some factors, the major of which is low contraceptive usage. [3]

Nigeria population was estimated to about One Hundred and Eighty Three (183) Million and the Seventh most populous in the world. The country has potential to reach an estimated population of Two Hundred and Eighty five (285) millions by 2050 [4].

Equally, it has been reported that there are about thirty five (35) million women of active reproductive age in the country while the number of births yearly is approximately seven (7) million. Total fertility rate in Nigeria is equally high as an average woman is capable of given births to 6 children [5]. In the light of the above, it is therefore important to adopt appropriate family planning practice which is affordable, accessible and safe as public health measure to reduce population growth in Nigeria [6].

Effective contraceptive will reduce number of attendance of high risk pregnancies maternal mortality rates.

Researches have equally shown that about $30 \%$ to $40 \%$ maternal mortality will be prevented if all women have equal access to contraception most especially in rural settlements. [7-9]

In industrialized countries, virtually all married women resort to contraception at some time in their reproductive period. In contrast, the proportion reporting such use in developing countries is extremely low. Nigeria which has a population number of 140 million and an, annual growth rate of $3.2 \%$ [10] is the most populous country in Africa. Nigeria, according to Omo-Aghoja et al (2011) [11] is already facing a population explosion with the resultant effect that food production cannot match the growing population. In Nigeria today, the birth rates are higher than the world averages [11]. Contraceptive Prevalence Rate (CPR) is still embarrassingly low in Nigeria, according to the report released by the International women's health coalition; the Contraceptive Prevalence Rate CPR among married women aged 15-49 years was $8 \%$ for modern methods and $12 \%$ for all methods. Also, other studies have reported a similarly low adoption rate of Modern Birth Control Methods [MBCM]. [12]

Available data indicates that Nigeria currently has one of the highest rates of maternal mortality in the world. It is also in evidence that $40 \%$ of these maternal deaths are due to complications of unsafe abortions, and abortion is a response to an unwanted pregnancy that could have been prevented by effective contraceptive programming. [13] Yet Nigeria's contraceptive prevalence rate is less than $13 \%$. The situation is further compounded by the persisting challenge of high fertility rate of about $5.8 \%$ and an annual growth rate of $2.8 \%$ in face of a large population size of about 183 million persons. [14] However, report shows that in the recent past decades, they are more records of investments in family planning programs which significantly increase the level of contraceptives use from $19 \%$ to $62 \%$ in the developing world with significant corresponding decline in fertility. [15]
Despite intensive programmatic efforts by the Nigerian government and various non-governmental agencies to reverse the trend, there has been little evidence to suggest a systematic improvement in these indicators most especially among rural women who are the focus of this study. Primary prevention at all levels of government targeting reduction in the numbers of at-risk pregnancies through effective contraception is therefore considered an important approach to resolving the problem. [16]

\section{Objectives of the Study}

The study was carried out to essentially determine the relationship between socio-demographic factors and contraceptive use among rural women, in order to achieve this, following were the objectives.

a) Determine the relationship between socio-demographic factors and contraceptive use;

b) Assess the level of knowledge and perception of rural women about modern contraceptive method;

c) Identify factors that serve as barriers associated with contraceptive use among rural women.

\section{Methodology}

\subsection{Study Location}

Ijero local government area is one of the local government area in Ekiti State of Nigeria in West Africa. Ijero Ekiti is the headquarters of Ijero Local Government since 1976. She has other component town under her control such as Ikoro Ekiti, Iroko Ekiti, Ayegunle Ekiti, Ipoti Ekiti, Iloro Ekiti, Temidire Ekiti, Ilukuno Ekiti, Epe Ekiti, Ara Ekiti, Araromi Ekiti, Oke Oro Ekiti, Odo Owa Ekiti and Ijurin-Ekiti. The population of Ijero Local Government was about 222,000 as it was shown with the 2007 population census. The majority of inhabitants are traders, artisans, and civil servants. Ijero local government has a state specialist hospital and numerous Primary Health Centers (PHCs) both comprehensive and basic sited at the headquarter i,e Ijero-Ekiti and its suburbs. It has tertiary institution such as College of Health Sciences and Technology, Ekiti State Cooperative College and Government Technical College located in Ijero Ekiti and many primary and secondary schools sited in the local government area.

\subsubsection{Study Design}

This study is a community-based, descriptive crosssectional study of socio-demographic factors and contraceptive use among women of reproductive ages (15-49 years) living in Ijero local government area of Ekiti State.

\subsubsection{Study Population}

The target populations are women of reproductive age, 15 to 49 years living in Ijero local government area of Ekiti state for at least 5 years. 


\subsection{Sample Size Estimation}

Using the sample size calculation formula for the calculation of sample size greater than 10000 , the sample for the study was determined. Based on evidence from recent Demographic and Health Survey (DHS) data, which indicated that only about 13 percent of sexually active Nigerian women currently practice effective contraception, the prevalence rate adopted in the study is $13 \%$, the confidence interval set at $95 \%$, normal deviation $\mathrm{Z}=1.96$ and $\mathrm{d}=0.05$.

The calculated sample size is $n=Z^{2} p q$ where

$\mathrm{d}^{2}$

$\mathrm{n}=$ sample size

$\mathrm{Z}=$ standard normal deviate set at 1.96 which correspond to the $95 \%$ confidence level.

$\mathrm{P}=$ Proportion of women with the knowledge of sexually active Nigeria women that practice contraceptives.

$\mathrm{d}=$ degree of precision $(0.05)$

$\mathrm{q}=1-\mathrm{P} 1-0.13=0.87$

$\mathrm{n}$ is therefore $=1.96^{2} \times 0.13 \times 0.87$ approximately 174

$0.05^{2}$

However, to increase representativeness and adjust for non response, the sample of 250 women between reproductive age 15-49years were selected.

\subsection{Sampling Method}

A multistage random sampling method was adopted for the study. This includes random selection of seven towns and villages out of fourteen towns that make up Ijero- Local government. Wards and streets were equally carved out from the selected towns and villages at different stages respectively and two hundred and fifty respondents were finally selected as estimated from the total population from different households in existing primary health care household numbering.

\subsection{Data Collection}

All eligible consenting women of reproductive age met in the sampled houses were interviewed with precoded, pretested, interviewer administered questionnaires. This was also conducted by trained research assistants who could also speak the local language. A vernacular version of the questionnaire was prepared for the uneducated respondents, to reduce inter observation variation in interpretation during the interview. The questionnaires were translated and backtranslated between the English and the local Yoruba language. Whenever a house was found to be empty, such houses were omitted, and the next even numbered houses were selected to replace it.

\section{Results and Discussion}

Socio-demographic characteristics of the respondents

Table 1 presents the distribution of respondents according to their background characteristics. In the study of this nature, socio-demographic characteristics of the respondents are very pertinent. Therefore, some selected characteristics such as age, marital status, educational level, work status and type of occupation were summarized in the table 1. Age distribution showed that they were young adult and largely in their reproductive age. About three quarter of the respondents were between age bracket 20 and 39 years. This segment of the sample is matured enough to take decision on modern contraceptive use. As regards their marital status, more than two third of them were married women and about one quarter were still single as at the time of survey. In addition, Christianity was more than other religions.

More than three-quarters were Christian, just 19\% constitute Muslim population in the sample and the remaining were traditional worshippers. A large number of the respondents were educated. In other words, nine out of every ten women were educated at least up to primary school level. More than two fifth have secondary school education, $39.8 \%$ have tertiary education and paltry $4.5 \%$ have never being to school. The distribution shows that women were largely educated in the study area. Furthermore, $84.9 \%$ of the respondents were Yoruba ethnic group. Also, $76.8 \%$ of the samples were working class. This shows that they can afford any of the modern conceptive if choose to. Occupation of the respondents was varied. More than one quarter of the respondents were petty traders. This of course constitutes the bulk of the sample. Students in the sample were $20.8 \%$ and civil servant constitutes $18.4 \%$. An awesome $36.4 \%$ of the respondents earn more than $\mathrm{N} 20,000$ as monthly incomes. This shows that respondents are financially capable as regards modern conceptive issues.

Table 1. Percentage distribution of respondents' background characteristics.

\begin{tabular}{lll}
\hline Characteristics & Frequency & Percentage \\
\hline Age group & & \\
Less than 20 years & 22 & 8.6 \\
20-29 years & 99 & 39.6 \\
$30-39$ years & 86 & 34.4 \\
$40-49$ years & 41 & 16.4 \\
50 years + & 2 & 0.8 \\
Total & 250 & 100 \\
Marital status & & \\
Single & 60 & 24.1 \\
Divorced/Separated & 18 & 7.2 \\
Married & 167 & 67.1 \\
Widow & 4 & 1.6 \\
Total & 249 & 100 \\
Religion & & \\
Christianity & 192 & 76.8 \\
Islam & 48 & 19.2 \\
Traditional & 5 & 2.0 \\
Total & 245 & 100 \\
Educational level & & \\
Informal education & 11 & 4.5 \\
Primary & 29 & 11.9 \\
Secondary & 107 & 43.9 \\
Tertiary & 97 & 39.8 \\
Total & 244 & 100 \\
Ethnicity & & \\
Yoruba & 208 & 84.9 \\
Igbo & 27 & 11 \\
Hausa & 6 & 2.4 \\
Others (Edo) & 4 & 1.6 \\
\hline
\end{tabular}




\begin{tabular}{lll}
\hline Characteristics & Frequency & Percentage \\
\hline Total & 245 & 100 \\
Currently working & & \\
Yes & 192 & 76.8 \\
No & 58 & 21.2 \\
Total & 250 & 100 \\
Type of occupation & & \\
Farming & 7 & 2.8 \\
Artisan & 36 & 14.4 \\
Petty trading & 69 & 27.6 \\
Full housewife & 8 & 3.2 \\
Business & 22 & 8.8 \\
Civil services & 46 & 18.4 \\
Professional & 10 & 4.0 \\
Students & 52 & 20.8 \\
Total & 250 & 100 \\
Income status & & \\
Less than 20000 & 102 & 40.8 \\
20000+ & 91 & 36.4 \\
Total & 193 & 100 \\
\hline
\end{tabular}

\begin{tabular}{lll}
\hline Knowledge & Frequency & Percentage \\
\hline Norplant & 6 & 2.4 \\
Female condoms & 47 & 18.8 \\
Intra uterine device & 27 & 10.8 \\
Implants & 23 & 9.2 \\
Source & & \\
Television & 76 & 30.4 \\
Radio & 126 & 50.4 \\
Hospital/clinic & 121 & 48.4 \\
Printed materials & 24 & 9.6 \\
Husband & 7 & 2.8 \\
School/friend & 11 & 4.4 \\
\hline
\end{tabular}

\section{Reasons for the type of modern contraceptives}

Several reasons were cited by the respondents to back up the type of modern contraceptive they use. The most popular reason among the women was the fact that injections, condoms and pill are easier to get. A number of women said they are readily available and have no side effect.

Knowledge of contraceptive use

From the table 2, it is evident that respondents have knowledge of contraceptive use. Nine out of every ten women have heard about contraceptive use. Respondents have used one type of conceptive method or the other. Injections method was the most popular conceptive method among the women in the study area. Next to this is male condoms and pill while male sterilization is the least type of conceptive method. However, the distribution shows that rural women used modern conceptive. In addition, source of information on contraceptive shows that they mostly heard it from radio and clinic. More than $30.4 \%$ of the respondents have heard it through television. Only $2.8 \%$ of the respondents heard it from their husband.

Table 2. Percentage distribution of respondents by knowledge about contraceptive use.

\begin{tabular}{lll}
\hline Knowledge & Frequency & Percentage \\
\hline Ever heard & & \\
Yes & 229 & 91.6 \\
No & 21 & 8.4 \\
Total & 250 & 100 \\
Type of contraceptive & & \\
Pill & 111 & 44 \\
Coil & 40 & 16 \\
Injections & 158 & 63.2 \\
Jelly/Spermicides & 9 & 3.6 \\
Condoms & 150 & 60 \\
Female sterilization & 7 & 2.8 \\
Male sterilization & 4 & 1.6 \\
\hline
\end{tabular}

Table 3. Reasons for chosen of modern contraceptive methods.

\begin{tabular}{lll}
\hline Reasons & Frequency & Percentage \\
\hline Easily affordable & 39 & 15.6 \\
Readily available & 25 & 10 \\
No side effect & 25 & 10 \\
Culturally acceptable & 3 & 1.2 \\
Religious acceptable & 2 & 0.8 \\
Husband consent & 7 & 2.8 \\
Influence of health pro & 10 & 4 \\
\hline
\end{tabular}

\section{Perceived benefit of modern contraception}

From the distribution in the table 4 , it is evident that women have considerable knowledge on different aspects of the modern contraceptives. In other words, respondents have better understanding of modern contraceptive methods. Nine out of every ten women perceived modern contraceptives as child spacing instruments. In addition, a number of women were of the view that modern contraceptive prevents unwanted pregnancy $(89.6 \%)$, regulation of family size $(87.6 \%)$, improve family life $(84 \%)$, improve mother and child health (78\%), irregular menstruation (74\%), Good for the mothers $(76.8 \%)$, weight gain $(71.2 \%)$, prevention of sexuality transmitted infections. However, few women perceived modern contraceptive as something that can boost husband fidelity (39.2\%).

Table 4. Percentage distribution of the respondents' perception about modern contraceptives.

\begin{tabular}{|c|c|c|c|c|}
\hline \multirow{2}{*}{ Items } & True & False & Don't know & Total \\
\hline & Freq. (\%) & Freq. $(\%)$ & Freq. (\%) & Freq. (\%) \\
\hline It enhances child spacing & $227(90.8)$ & $9(3.6)$ & $14(5.6)$ & $250(100)$ \\
\hline Prevention of unwanted pregnancy & $224(89.6)$ & $13(5.2)$ & $13(5.2)$ & $250(100)$ \\
\hline Regulation of family size & $219(87.6)$ & $13(5.2)$ & $18(7.2)$ & $250(100)$ \\
\hline Improve family life & $210(84)$ & $16(6.4)$ & $24(9.6)$ & $250(100)$ \\
\hline Improve mother and child health & $195(78)$ & $24(9.6)$ & $31(12.4)$ & $250(100)$ \\
\hline Good for the mothers & $192(76.8)$ & $21(8.4)$ & $37(14.8)$ & $250(100)$ \\
\hline Prevention of sexuality transmitted & $150(60)$ & $73(29.2)$ & $27(10.8)$ & $250(100)$ \\
\hline Boost husband's fidelity & $98(39.2)$ & $95(38)$ & $53(22.8)$ & $250(100)$ \\
\hline
\end{tabular}


Relationship between use of modern contraceptives and some selected socio-demographic variables

Table 5 presents the summary of the relationship between modern contraceptives use and some selected sociodemographic characteristics. The distribution revealed that women of reproductive age made use of contraceptive. Women in age bracket $40-49$ year made use of modern contraceptive than any other age group (68.3\%). A Chi square test revealed a significant relationship between age and modern contraceptive use $\left(\chi^{2}=16.826, \mathrm{p}<0.05\right)$. About three quarter $(72.2 \%)$ of divorced women used modern contraceptive, $49.1 \%$ of the married and one quarter (26.7) of the single used modern contraceptive. A test of relationship between marital status and use of modern contraceptive showed a significant relationship $\left(\chi^{2}=19.330, \mathrm{p}<0.05\right)$

In addition, all the religious groups made use of modern contraceptive. However, a Chi square statistics showed that there exist no significant relationship between religion and contraceptive use $\left(\chi^{2}=0.250, \mathrm{p}>0.05\right)$. The distribution further revealed that modern contraceptive use cut across the educational level. A Chi square test of independence revealed that there is no significant relationship between educational status and conceptive use $\left(\chi^{2}=2.757, \mathrm{p}>0.05\right)$. Furthermore, a number of higher income earner utilized modern contraceptive. A Chi square test of independence revealed a significant relationship between income and contraceptive use $\left(\chi^{2}=5.157, \mathrm{p}<0.05\right)$.

Table 5. Relationship between use of contraceptives and some selected socio-demographic variables.

\begin{tabular}{|c|c|c|c|c|c|}
\hline \multirow{3}{*}{ Variables } & \multicolumn{3}{|c|}{ Contraceptive use } & \multirow{3}{*}{$\begin{array}{l}\text { Statistics } \\
\chi^{2}\end{array}$} & \multirow{3}{*}{ p-value } \\
\hline & Yes & No & Total & & \\
\hline & Freq. (\%) & Freq. (\%) & Freq. (\%) & & \\
\hline \multicolumn{6}{|l|}{ Age group } \\
\hline $20-29$ years & $40(40.4)$ & $59(59.6)$ & 99 (100) & \multirow{6}{*}{16.826} & \multirow{6}{*}{0.002} \\
\hline $30-39$ years & $42(50)$ & $42(50)$ & $84(100)$ & & \\
\hline $40-49$ years & $28(68.3)$ & $13(31.7)$ & $41(100)$ & & \\
\hline 50 years + & $1(50)$ & $1(50)$ & $2(100)$ & & \\
\hline \multirow{2}{*}{\multicolumn{4}{|c|}{$\begin{array}{l}\text { Total } \\
\text { Marital status }\end{array}$}} & & \\
\hline & & & & & \\
\hline Single & $16(26.7)$ & $44(73.3)$ & $60(100)$ & \multirow{5}{*}{19.330} & \multirow{5}{*}{0.000} \\
\hline Divorced & $13(72.2)$ & $5(27.8)$ & $18(100)$ & & \\
\hline Married & $81(49.1)$ & $84(50.9)$ & $165(100)$ & & \\
\hline Widow & $4(100)$ & - & $4(100)$ & & \\
\hline \multicolumn{4}{|l|}{ Religion } & & \\
\hline Christianity & $89(46.8)$ & $101(53.2)$ & $190(100)$ & \multirow{3}{*}{0.250} & \multirow[b]{2}{*}{0.969} \\
\hline Islam & $23(47.9)$ & $25(52.1)$ & $48(100)$ & & \\
\hline \multicolumn{5}{|l|}{ Education } & \\
\hline No education & $4(36.4)$ & $7(63.6)$ & $11(100)$ & \multirow{4}{*}{2.757} & \multirow{4}{*}{0.431} \\
\hline Primary & $12(41.4)$ & $17(58.6)$ & $29(100)$ & & \\
\hline Secondary & $45(42.9)$ & $60(57.1)$ & $105(100)$ & & \\
\hline Tertiary & $51(52.6)$ & $46(47.4)$ & $97(100)$ & & \\
\hline \multicolumn{6}{|l|}{ Income } \\
\hline Less than 2000 & $44(44)$ & $56(56)$ & $100(100)$ & \multirow{2}{*}{5.157} & \multirow{2}{*}{0.017} \\
\hline $2000+$ & $55(60.4)$ & $36(39.6)$ & $91(100)$ & & \\
\hline
\end{tabular}

Reasons for non-use of modern contraceptives among rural women

Table 6 shows different reasons that were given for the non-use of modern contraceptive by the women. Meanwhile, the most popular reason for non-use of modern contraceptive is negative attitude people have against it $(40.8 \%)$. In addition, the next reasons are fear of side effect (40.4\%), desire for more children (38\%) and perceived low risk of getting pregnant $(36 \%)$. It could therefore be deduced that poor accessibility to health care facilities was the least reason for non-use of modern contraceptive among the women.

Table 6. Percentage distribution of reasons for non-use of modern contraceptives.

\begin{tabular}{|c|c|c|c|c|}
\hline \multirow{2}{*}{ Items } & True & False & Don't know & Total \\
\hline & Freq. (\%) & Freq. (\%) & Freq. (\%) & Freq. (\%) \\
\hline Negative attitude & $102(40.8)$ & $56(22.4)$ & $92(36.8)$ & $250(100)$ \\
\hline Fear of side effect/complication & $101(40.4)$ & $63(25.2)$ & $80(34.4)$ & $250(100)$ \\
\hline Desire for more children & $95(38)$ & $70(28)$ & $85(34)$ & $250(100)$ \\
\hline Perceived low risk of getting $\mathrm{p}$ & $90(36)$ & $56(22.4)$ & $104(41.6)$ & $250(100)$ \\
\hline Religious unaccepted & $68(27.2)$ & $97(38.8)$ & $85(34)$ & $250(100)$ \\
\hline Partner non approval & $63(25.2)$ & $94(37.6)$ & $93(37.2)$ & $250(100)$ \\
\hline Traditionally unaccepted & $37(14.8)$ & $113(45.2)$ & $100(40)$ & $250(100)$ \\
\hline Culturally not accepted & $34(13.6)$ & $112(44.8)$ & $104(51.6)$ & $250(100)$ \\
\hline Low level of income & $30(12)$ & $133(53.2)$ & $87(34.8)$ & $250(100)$ \\
\hline Poor accessibility to health care & $22(8.8)$ & $145(58)$ & $83(33.2)$ & $250(100)$ \\
\hline
\end{tabular}




\section{Discussion}

This study was designed to essentially determine the relationship between socio-demographic factors and contraceptive use. This was with the view of identifying existing barriers to contraceptive use in the county. The study adopted a community-based, descriptive cross-sectional study. The target population was women of reproductive age, 15 to 49 years living in Ijero Local Government Area of Ekiti State. Using the sample size calculation formula, a sample of 250 women was randomly selected for the study. Data was collected using a questionnaires translated and backtranslated between the English and the local Yoruba language. Data analysis was performed using SPSS version 20 to generate descriptive and inferential statistics such as contingency tables and bar charts. Chi square was used to find relationship between non parametric variables by testing for association at $5 \%(p=0,05)$ level of significance.

Key findings of the study reveals that: respondents were young adults and largely in their reproductive age span; more than three-quarters were Christian; more than two-fifths have secondary school education, $76.8 \%$ of the sample were working; nine out of every ten women have heard about contraceptives: this is similar to the studies conducted by National Population Commission and ICF in 2014 [5] in which general knowledge of contraceptives was high while the adoption is low as only fifteen (15) percent of the married women of reproductive age are using any contraceptive method many respondents have used at least one type of contraceptive method Injections method was the most popular conceptive method among the respondents as earlier reported Ahmed et al 2012 [7] and more than 30.4\% of the respondents heard about contraceptives through television which equally correlates to the findings of Oye-Adeniran et al 2006 [17] who reported that friends, media and health workers are found to be the main source of information on family planning program in the country.

Results further show that women have considerable knowledge on different aspects of the modern contraceptives; $89.6 \%$ of women were of the view that modern contraceptive prevents unwanted pregnancy; $39.2 \%$ perceived modern contraceptive as something that can boost husband fidelity (39.2\%); the most common negative effect of modern contraceptives reported is irregular menstruation among the users; and women in the study area have used injections (22\%) and condoms $(20.8 \%)$ more than any other modern contraceptive methods. This finding is similar to the results of previous studies by Solanke (2017) and AsekunOlarinmoye et al 2013. [18, 19] The results of the chi-square tests show that age and modern contraceptive use were significantly associated $\left(\chi^{2}=16.826, \quad \mathrm{p}<0.05\right)$ which correlates to the previous studies [18] marital status and use of modern contraceptive were significant related $\left(\chi^{2}=19.330\right.$, $\mathrm{p}<0.05)$; this equally corroborates previous studies by Adebayo et al [20] and nine out of every ten women perceived modern contraceptives as child spacing instruments [19] no significant relationship between religion and contraceptive use $\left(\chi^{2}=0.250, \mathrm{p}>0.05\right)$ and no significant relationship between educational status and conceptive use $\left(\chi^{2}=2.757, \mathrm{p}>0.05\right)$; however these are in contrast to the most findings of the previous studies which may be attributed to higher percentage of Christian respondents that gained considerable advantages over other religions in the study area and equally majority of the respondents attended at least secondary education which had influenced their informed decisions on adoption of contraceptives.

Income and contraceptive use were significantly associated $\left(\chi^{2}=5.157, \mathrm{p}<0.05\right)$ which is similar to previous studies by Ibisomi, 2014 [21] who reported that women of low socioeconomic status have lower uptake rate of contraceptives.

\section{Conclusion}

This study was essentially carried out to examine the socio-demographic factors affecting contraceptive use among rural women in the rural settlement of Ijero local government area of Ekiti state Nigeria. Primary data were generated from the respondents, the results showed that socio-demographic factors analyzed in the study such as age, marital and socioeconomic status were more significantly associated with contraceptive use as it correlate to similar studies, however in contrast to most studies, education and religion have no significant relationship with the contraceptive use in the study. Equally, most of the respondents have general knowledge about the contraceptives however, higher proportion of women in the study area attributed non use of contraceptives to negative attitude and fear of side effects. This is capable of hampering adoption of contraceptives among the rural women if it is not addressed.

Programs and policies at all levels of government should therefore pay more attention on influencing women's sociodemographic characteristics and perceived side effects associated with contraception in order to reduce the unmet needs of rightful adoption of family planning among rural women.

\section{Recommendations}

From the study carried out, it was recommended that government should make usage of modern contraceptives as a national health priority.

Efforts should be made to improve and sustain awareness of modern contraceptives through community-based behavioral-change communication program aimed at improving the awareness and perceptions of women with respect to desire for more children, and bridging the knowledge gaps about contraceptive methods, and at changing the odd beliefs related to rightful adoption of contraceptive.

Attention should be made by the government to make contraceptive free or highly subsidized to make it accessible to rural women of low socio-economic status. 


\section{References}

[1] Braddocks, J. (1977). Reading in Social Problem. Dushkin Pub. Group Inc. pp193-199.

[2] Kalambayi Patrick. (2006). Prevalence and determinants of the use of modern contraceptive methods in Kinshasa, Democratic Republic of Congo. Contraception; 74 (5): 400406.

[3] Kartikeyan S, Chaturvedi RM. (1995). Family planning: views of female non-acceptors in rural India. J Postgrad Med; 41: $37-9$.

[4] United Nations. 2013. World population prospects, the 2012 revisions: Key findings and advance tables. New York: United Nations.

[5] National Population Commission and ICF International, and 2014. Nigeria demographic and health survey (NDHS). edited by National Population Commission. Abuja-Nigeria, Rockville, Maryland USA National Population Commission and ICF International.

[6] Graff, M., and J. Bremner. 2014. A practical guide to population and development Washington: Population Reference Bureau.

[7] Ahmed, S., Q. Li, L. Liu, and A. O. Tsui. 2012. "Maternal deaths averted by contraceptive use: Analysis of 172 countries." The Lancet 380 (9837): 111-125.

[8] Cleland, J. G., R. P. Ndugwa, and E. M. Zulu. 2011. "Family planning in Sub-saharan Africa: Progress or stagnation?" Bulletin of the World Health Organization 89: 137-143.

[9] Collumbien, M., M. Gerressu, and J. Cleland. 2004. Non-use and use of ineffective methods of contraception. Edited by Majid Ezzati, Alan D. Lopez, Anthony Rodger, and Chrstopher J. L. Murray. Vol. 2, Comparative quantification of health risks: Sexual and reproductivehealth. Geneva: World Health Organization.

[10] NPC (1999 \& 2006), National Population Commission.
[11] Omo-Aghoja LO, Hammed A, Okonofua FE, Okpani OA, Koroye OC, Ojobo S, Qual Prim et al ( 2011) Care.; 19 (5): 325-34.

[12] Donati S, Hamam R, Medda E. (2000). Family planning KAP survey in Gaza. Soc Sci Med; 50: 841-9.

[13] Johnson-Hanks. (2002). Time and Social Context of Fertility. Population and Development Review; 28 (2) 229-249.

[14] Bongaarts J. (1982). The fertility inhibiting effects of the intermediate fertility variables. Studies in family planning, 13 (617): 179-89.

[15] Greanga, A. A., D. Gillespie, S. Karklins, and A. O. Tsui. 2011. "Low use of contraceptive among poor women in Africa: An equity issue." Bulletin of the World Health Organization 9: 258-266.

[16] Bassey EA, Abassattai AM, Asuquo EE, Udoma EJ, Oyo-ita A. (2005). Awareness, attitude and practice of contraception among secondary school girls in Calabar. Nigerian Journal of Medicine; 14 (2): 146-150.

[17] Oye-Adeniran, B., I. F. Adewale, A. V. Umoh, A. Oladokun, A. Gbadegesin, and E. E. Ekanem. 2006. "Community-based study of contraceptive behavior in Nigeria." African Journal of Reproductive Health 10 (2): 90-104.

[18] Solanke B. L Journal of Health, Population and Nutrition (2017) 36: 1 DOI 10.1186/s41043-016-0077-6.

[19] Asekun-Olarinmoye E O Adebimpe, W O Bamidele, JO Odu, OO Asekun-Olarinmoye, I O and Ojofeitimi EO Int J Womens Health. 2013; 5: 647-655. Published online 2013 Oct 11. doi: 10.2147/IJWH.S47604.

[20] Adebayo, S., E. Gayawan, C. Ujuju, and A. Ankomah. 2012. "Modelling geographic variation in use of modern family planning methods among women of reproductive age in Nigeria." Journal of Biosocial Science 00: 1 (28).

[21] Ibisomi, L. 2014. "Are differences between partners associated with contraceptive use among married couples in Nigeria?" International Perspectives on Sexual and Reproductive Health 40 (1): 39-45. 